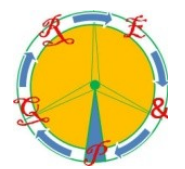

\title{
Unfavourable Reactive Power in a Rolling Mill
}

\author{
Stanislav Nowak, Stanislav Kocman \\ ${ }^{1}$ Department of General Electrical Engineering \\ VŠB - Technical University of Ostrava \\ Ostrava, Czech Republic \\ Phone: +420 597325 921,+420 597325922 e-mail: stanislav.nowak.st@vsb.cz, stanislav.kocman@vsb.cz
}

\begin{abstract}
The electrical consumption of the rolling mill is usually very high, above $10 \mathrm{MW}$, and significantly changes during the rolling process. The rolling mill drives consume not only active but also reactive inductive power. This reactive consumption is directly compensated in the rolling mill. In order to achieve feasible energy efficiency, it is necessary to maintain balance between the instantaneous reactive inductive consumption of the drives and the instantaneous capacitive consumption of the compensating devices. The results of the consumption measurements in the real working rolling mill are presented and discussed in this paper.
\end{abstract}

Key words. Active power, reactive power, rolling mill, drive, compensation

\section{Introduction}

Steel is one of the basic materials necessary for a modern civilized society. A steel consumption per capita is often used as a measure of the degree of development of the community. The vast majority of steel is produced in the form of rolled products; there are long, wide-thin and wide-thick products. The process is called rolling; there are hot rolling and cold rolling. Rolling is also used for treatment of other non-iron metals [1].

Rolling is a metal forming process in which a metal stock is passed through one or more pairs of the rolls to reduce its thickness [1] and to make the profile of rolled material uniform and correct. A roll gap (the gap between the working rolls) is smaller than the thickness of the entering metal profile. The rolling rolls are held in the working position in a massive frame, with which they form the basic unit of the rolling process - the rolling stand, see Fig. A. The rolling mill is a series of rolling stands placed one behind the other. The rolled material always passes gradually from one stand to the next stand and thus passes through the entire line. Rolling is therefore a forming process that requires a large amount of mechanical energy. In the described rolling mill the rolling stands are driven

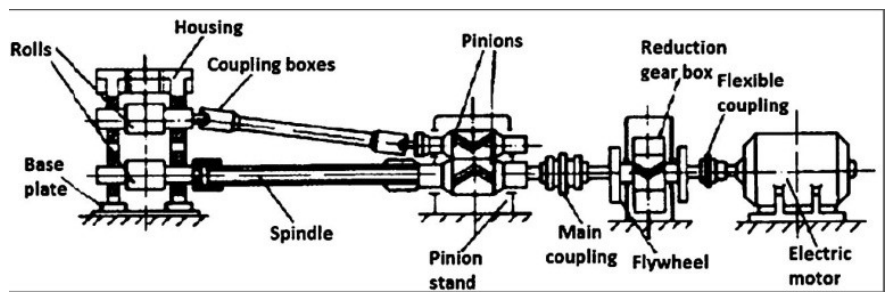

Fig. 1. The components of the rolling stand [1] by DC motors. The rolling process requires a precision control of the speed of these motors. The controlled rectifiers are used for this.

\section{The rolling mill drives}

Mechanical energy in the form of a rotation movement of the rolls against the resistance of the rolled material is generated in the large electric motor. The rotational speed of this motor must be very rapidly and precisely controllable in conditions of a quickly and violently varying mechanical load. The asynchronous motors, in combination with the frequency converters, are used to drive the stands in the newly built rolling mills. Earlier, practically from the beginning of the use of continuous rolling technology, the DC motors were used for driving the rolling stands [2]. The DC motors are more expensive than the $\mathrm{AC}$ asynchronous motors and also much more difficult and expensive to maintain. The power supply of these motors was provided by the electro-mechanical rotary converters, usually called the Ward Leonard control system. This converter is a combination of an AC motor and a DC generator. Thus, each stand has its power DC generator for its electrical power supply. It is possible to change the output voltage of the DC generator by simple DC generator excitation control. From the point of view of powering the rolling stands, in this concept the rolling stands are driven by uncontrolled AC motors with the mechanical-electrical and reverse electro-mechanical energy conversion. Described historical solution, which fulfils the function of a controlled rectifier, is very expensive, energy inefficient, requires a lot of space, and the equipment is difficult to maintain. However, the AC motors represent the harmonic loads, and in the case of a partial use of the AC synchronous motors for Ward Leonard system or systems (in the case of structured supply system) it is possible by the control of the excitation currents of the AC synchronous motors to control the resulting power factor of the whole rolling mill. Such historical concept also significantly reduces a grid voltage distortions and disturbances. The large inertial mass of the rotating machine acts as an accumulator of mechanical energy, which the AC synchronous motor uses to compensate for the missing or excess energy in the supply system.

In the investigated rolling mill, all the stands are driven by the DC motors, which are powered by the controlled thyristor rectifiers usually called "DC converters" in the 
text below. Every stand, and therefore every DC motor, has its own MV/LV supply transformer transforming the electric energy from the level of $6 \mathrm{kV}$ on its specific supply voltage $(500 \mathrm{~V}, 690 \mathrm{~V}$, and $750 \mathrm{~V})$. The MV/LV transformers are in $\mathrm{D} / \mathrm{y}$ or $\mathrm{Y} / \mathrm{y}$ connection. All motors are equipped with speed transmitters that are connected to the DC converters as a feedback. The feedback control allows an exact setting of the required speed and also ensures a high stability of the driver speed. The input current of the DC converter changes very quickly depending on the actual mechanical load of the drive.

\section{Electric supply system in the rolling mill}

The use of the combination of the DC converter and the DC motor is accompanied by the non-harmonic current consumption from the AC supply [3].The DC motor is the inductive-active load and the DC converter output voltage is not smoothed. The thyristor phase control also results in a phase shift between the voltages and currents of the individual harmonics. Voltages and currents of the fundamental frequency are considerably phase-shifted. This circumstance requires the installation of the devices that reduce the consequences of the negative phenomena mentioned [4]. For this purpose, two different units are used in the investigated rolling mill.

The older unit, the AC MV synchronous motor, which serves as a synchronous condenser (rotating compensator), is used for the reducing of the content of harmonics in the final currents at the input of the rolling mill power system. Its effect is broadband, so it filters harmonics regardless of their frequency. At the same time, it serves as controllable reactive power compensator [5].

The newer device, the static filter-compensation unit for the filtering of the harmonics and at the same time for the compensating of the undesired reactive power, is composed of the series resonant circuits for the $3^{\text {rd }}$ and $5^{\text {th }}$ harmonics. The total compensating power of this filtercompensation unit (in next FCU) is 5.8 Mvar; the value of this capacitive compensating power cannot be controlled. The described units are located in two different places of the rolling mill but work together on the MV bus on the level of $6 \mathrm{kV}$. The connection between the main substation $\mathrm{R} 2$ and the appended substation R5 is a relatively long MV cable line.

The electric power from the public $110 \mathrm{kV} / 50 \mathrm{~Hz}$ grid is transformed in the power transformer $\mathrm{T} 2$ to the level of $22 \mathrm{kV}$. The subsequent power transformer TP2 is used only for the investigated rolling mill; it transforms the voltage of $22 \mathrm{kV}$ to the level of $6 \mathrm{kV}$. Most of the rolling mill's drives are supplied at the $6 \mathrm{kV}$ level directly from the main substation R2. The new rolling stands were added during several upgrades. These stands also required power connection, but it was not possible to expand the main substation R2. Therefore, the new appended substation R5 was designed and built.

The basic block diagram of the rolling mill is shown in Fig. 2.

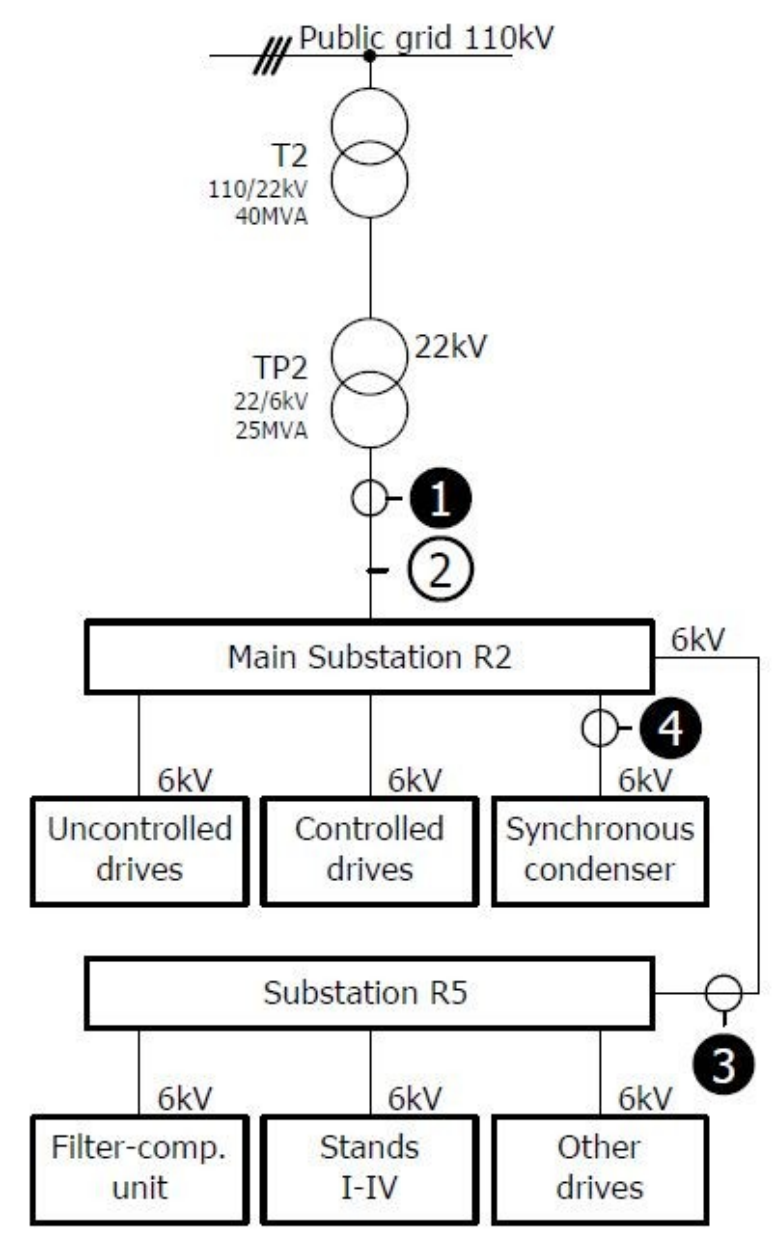

Fig. 2. Basic block diagram of the rolling mill power system

\section{Substation R5}

The four very important rolling stands (Stands I to IV) are powered from the substation R5, which the filtercompensation unit is also connected in. The substation R5 was added in 2005 due to the major expansion of the rolling mill. That year, four mentioned large rolling stands were added at the entrance of the rolling line. These rolling stands allowed the modification from the rolling $100 \mathrm{~mm}$ thick billets to $140 \mathrm{~mm}$ billets. The other stands were also added, but these were not active at the time of the measurement. The other auxiliary simple drives are powered from the substation. The peak consumption of the whole station can reach up to 10 MW. Therefore, it was decided to add the new filtercompensation unit to the main supply system of the rolling mill. Building of the new substation R5 was a good opportunity to install the new filter-compensation unit. The FCU works stably and reliably for almost 16 years. The FCU is equipped with circuits which, in the event of a fault, enable the detection of defective capacitors. Simplified single line diagram of the substation R5 is shown in Fig. 3. The individual MV/LV transformers are in $\mathrm{Y} / \mathrm{y}$ or $\mathrm{D} / \mathrm{y}$ connections. The all rectifiers are precisely controlled by the control system. Both sections of the FCU work on the voltage level of $6 \mathrm{kV}$. 


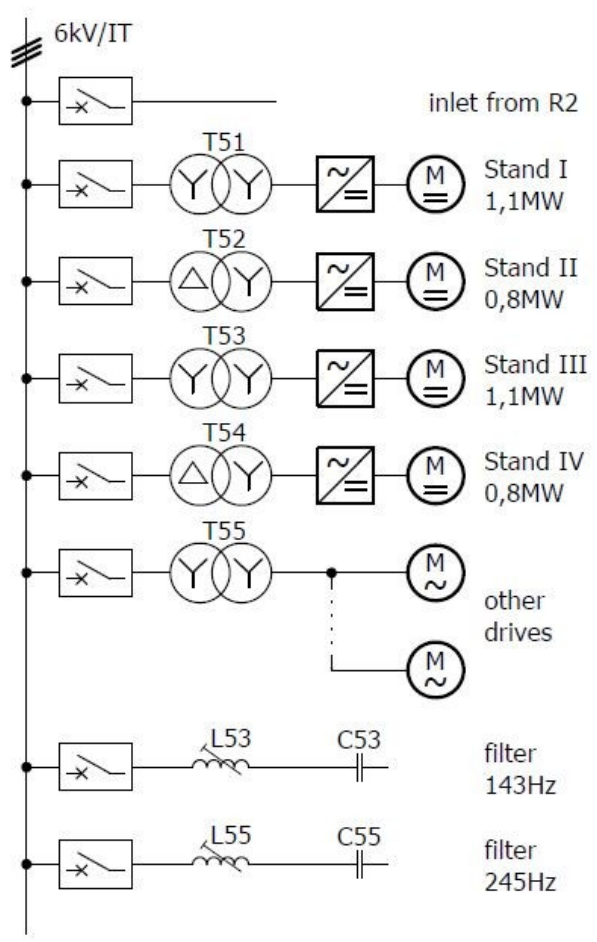

Fig. 3. Simplified single line diagram of the substation R5

\section{Measurement of the power}

The measurement of the active and reactive power was possible only in some points of the main substation R2. Unfortunately, it was not possible to measure in the appended substation R5. The main inlet to substation R2, the cable outlet to the appended substation R5 and the outlet to the synchronous condenser were investigated. The measuring points are shown in Fig. 2. The currents were measured at the points 1,3 , and 4 . Since all these points work at a common potential, the necessary voltages were obtained from the common voltage point 2 . The point 1 was used for the measurement of the total consumption of the whole rolling mill; the point 3 was used for the measurement of the consumption of the appended substation R5, and the point 4 was used for the measurement of the consumption of the synchronous condenser.

A network analyser C.A 8335 Qualistar+ was used for the measurement [6]. It is the three-phase network analyser with a colour graphic display. The analyzer is easy to carry, it is designed for demanding industrial conditions. The instrument allows the displaying of instantaneous measured values and at the same time, recording of measured and calculated data into a file. The shortest record period is one second; this record period was chosen. The selected recorded values were converted into the graphs in the form of the time courses of the monitored powers. The recording time each time exceeded $5 \mathrm{~min}$, so that more than 300 records were obtained at each measured point. The analyser can display a phasor presentation of the voltages and currents called a Fresnel diagram. Snapshots of the Fresnel diagrams were taken and saved during the measurement. The phase shifts between the voltage and current phasors are well visible in the recorded Fresnel diagrams.
The measurements were performed within 40 minutes. Unfortunately it was not possible to measure at the individual points simultaneously. During these 40 minutes, the whole rolling mill worked evenly and stably, so the recorded power time courses can be assessed in the time context. The mentioned time courses show considerable regularity and periodicity, which testifies to the stable and therefore desirable operation of the rolling mill. The individual cycles correspond to the processing of one billet. The insignificant differences of individual cycles are caused by differences in plasticity and weight of individual billets. In Fig. 4 is shown the time course of the total consumption of the rolling mill during four cycles, which represent processing of four pieces of two ton hot billets.

The rolling mill also includes a heating furnace with various drives, the operation of which is not synchronized with the rolling process itself. These drives have their own operation program, which also causes some irregularities during this time course.

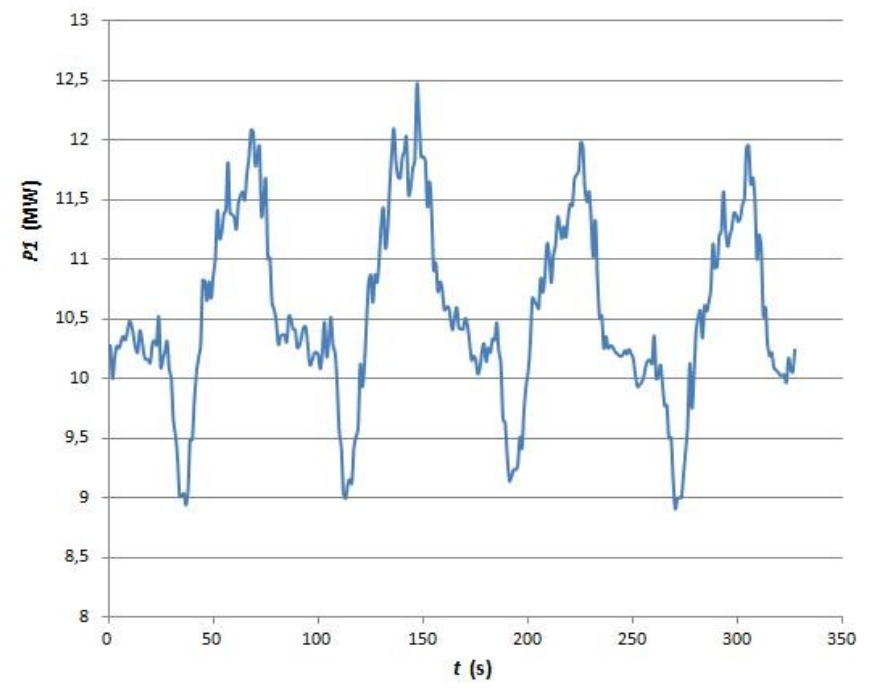

Fig. 4. Time course of the rolling mill active consumption $P_{1}$

\section{Measured time courses}

The largest time changes were found in the consumption of the substation R5. Such a finding was expected from this substation. At the time of the measurement, especially the Stands I to IV showed very significant changes in both active and reactive consumption. Other non-controlled auxiliary drives had more or less stable consumption of approx. $1 \mathrm{MW}$.

In the time course of the active consumption $P_{3}$ it is easy to see the billet pass through the individual Stands I to IV over the one rolling cycle. The billet gradually enters the individual stands and the consumption $P_{3}$ gradually increases in four levels. For a short time, the billet is rolled by all stands, whereon it leaves the individual stands, so the consumption $P_{3}$, on the contrary, gradually decreases likewise in four levels. When the Stands I to IV do not work, the substation has the stable active consumption $P_{3}$ of approx. $1 \mathrm{MW}$. During the idle state of the Stands I to IV, the measured reactive capacitive consumption $Q_{3}$ was approximately $5.2 \mathrm{Mvar}$. The total capacitive consumption of the connected filter- 
compensation unit (FCU) is almost 5.8 Mvar. The main parameters of the FCU are shown in Table I.

Table I. - The selected parameters of the FCU

\begin{tabular}{|c|c|c|c|}
\hline Parameter & Value & Parameter & Value \\
\hline Max. reactive & $5791 \mathrm{kVAr}$ & $1^{\text {st }}$ filtering & 143 \\
consumption & & frequency & $\mathrm{Hz}$ \\
\hline Nominal voltage & $6000 \mathrm{~V}$ & $2^{\text {nd }}$ filtering & 245 \\
& & frequency & $\mathrm{Hz}$ \\
\hline
\end{tabular}

It follows that $0.6 \mathrm{Mvar}$ of the compensating reactive power is used to compensate the active consumption of the auxiliary drives. During the operation of the Stands I to IV, the active consumption $P_{3}$ gradually increases by $2.2 \mathrm{MW}$, reciprocally, the reactive consumption $Q_{3}$ decreases by 2.2 Mvar. This means that the capacitive reactive consumption of 2.2 Mvar is required to compensate the inductive reactive consumption of the Stands I to IV during their full operation. The substation as a whole is therefore significantly overcompensated, the excess capacitive reactive consumption is used at the rolling mill to compensate the reactive consumption of other drives not connected to the substation R5. The time courses of the active consumption $P_{3}$ and capacitive reactive consumption $Q_{3}$ are shown in Fig. 5 and Fig. 6.

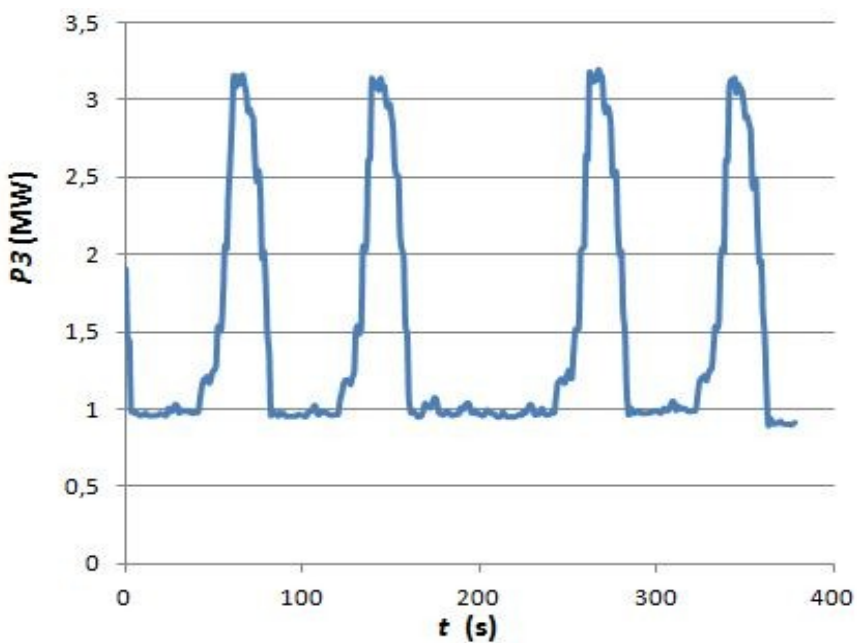

Fig. 5. Active consumption $P_{3}$ of the substation R5

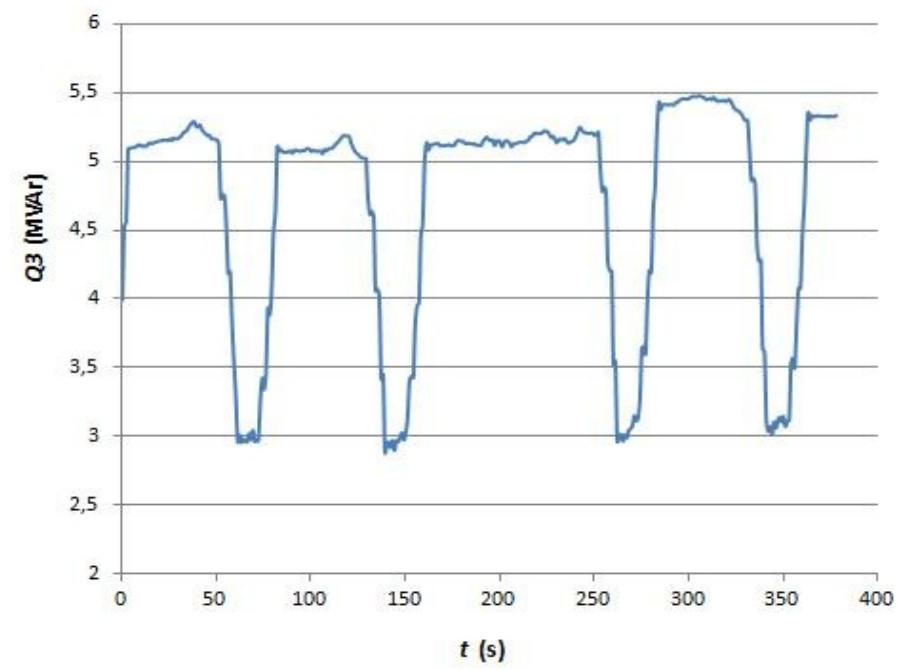

Fig. 6. Reactive consumption $Q_{3}$ of the substation R5
The consumption measurement of the synchronous condenser was less interesting but very important. The time course of active consumption $P_{4}$ is relatively stable. The active consumption $P_{4}$ varies from $74 \mathrm{~kW}$ to $82 \mathrm{~kW}$. Also the capacitive reactive consumption $Q_{4}$ does not change much over time. The approximate mean value of the capacitive reactive consumption $Q_{4}$ is 1 Mvar. Maximum deviation from this value does not exceed 100 kvar.

During the evaluation of the measurement results, it was found by the inquiry of the rolling mill operator that the excitation current of the synchronous condenser is fixed and this setting does not change during the entire operation of the compensator. The possibility of the control of the reactive consumption of the synchronous condenser is not utilized here. The name plate parameters of the synchronous condenser are shown in Table II.

Table II. - The main parameters of the condenser

\begin{tabular}{|c|c|c|c|}
\hline Parameter & Value & Parameter & Value \\
\hline $\begin{array}{c}\text { Rated reactive. } \\
\text { power }\end{array}$ & $\begin{array}{c}6.5 \\
\text { Mvar }\end{array}$ & $\begin{array}{c}\text { Rated excitation } \\
\text { DC current }\end{array}$ & $365 \mathrm{~A}$ \\
\hline Rated voltage & $6000 \mathrm{~V}$ & $\begin{array}{c}\text { Rated excitation DC } \\
\text { voltage }\end{array}$ & $84 \mathrm{~V}$ \\
\hline Max. current & $627 \mathrm{~A}$ & Frequency & $50 \mathrm{~Hz}$ \\
\hline
\end{tabular}

The time courses of the active consumption $P_{4}$ and capacitive reactive consumption $Q_{4}$ are shown in Fig. 7 and Fig. 8.

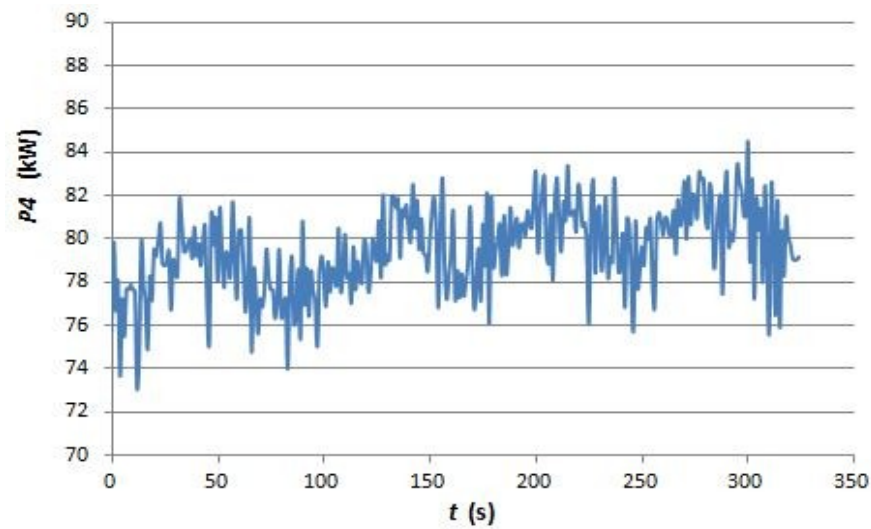

Fig. 7. Active consumption $P_{4}$ of the synchronous condenser

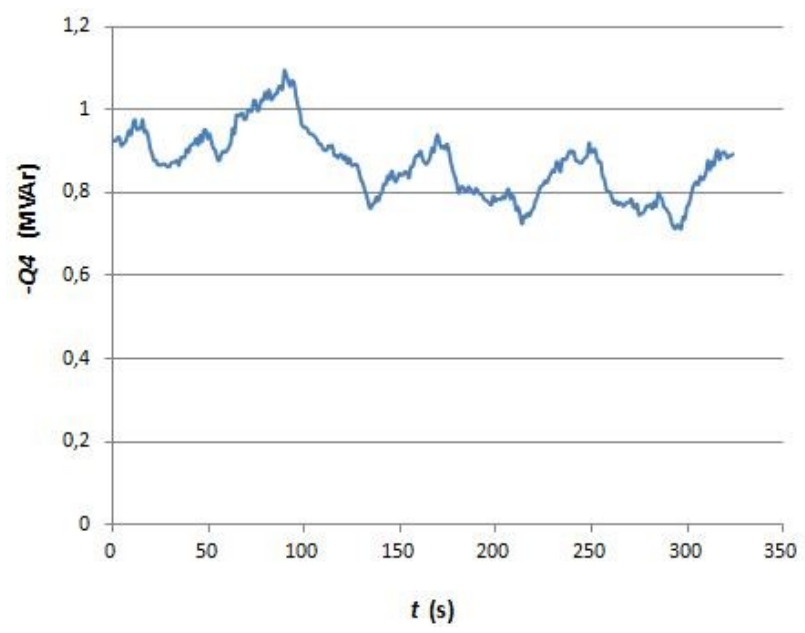

Fig. 8. Reactive consumption $Q_{4}$ of the synchronous condenser 
Of course, the most interesting are the time courses of the total active and reactive consumption of the rolling mill at its inlet. The whole active consumption $P_{1}$ during the rolling cycle varies from $8.7 \mathrm{MW}$ to $12.5 \mathrm{MW}$.

The time course of reactive consumption $Q_{1}$ is not favourable. In order to achieve minimum losses on the supply lines and supply transformers, it is necessary that the absolute value of reactive consumption is as small as possible. However, this is not the case here. The value of $Q_{1}$ varies from $0.7 \mathrm{Mvar}$ of capacitive reactive consumption to $2.3 \mathrm{Mvar}$ of inductive reactive consumption.

For most of the rolling cycle, the rolling mill is inadequately compensated. The possibility of the capacitive reactive consumption of the synchronous condenser is far from being used.

For the rest of the rolling cycle, the rolling mill is unnecessarily overcompensated. The time courses of the active consumption $P_{1}$ is shown in Fig. 4 and the reactive consumption $Q_{1}$ is shown in Fig. 9. The Fresnel diagram showing all voltages and currents at the moment of the $37^{\text {th }}$ second is in Fig. 10. The positions of the phasors clearly prove capacitive character of consumption at this moment.

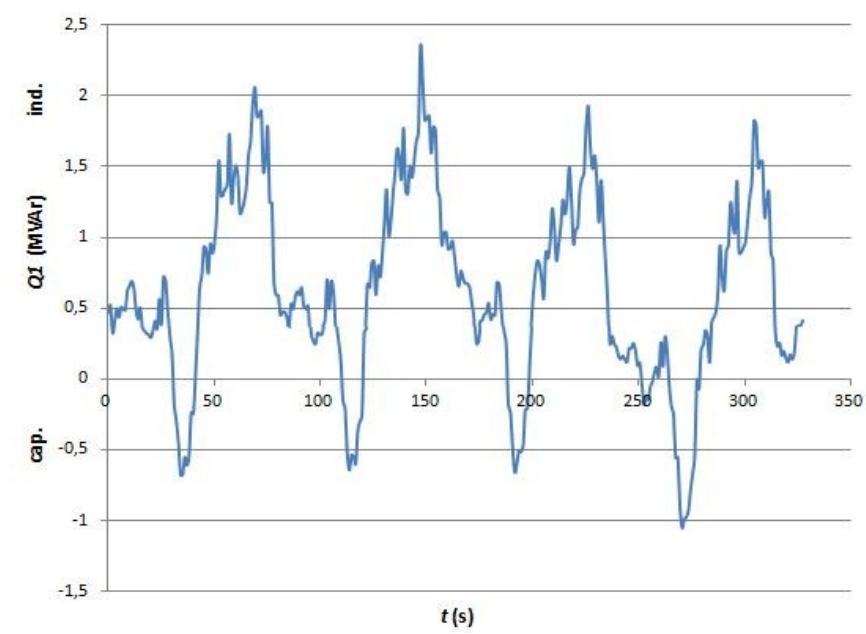

Fig. 9. Total reactive consumption $Q_{1}$ of the rolling mill

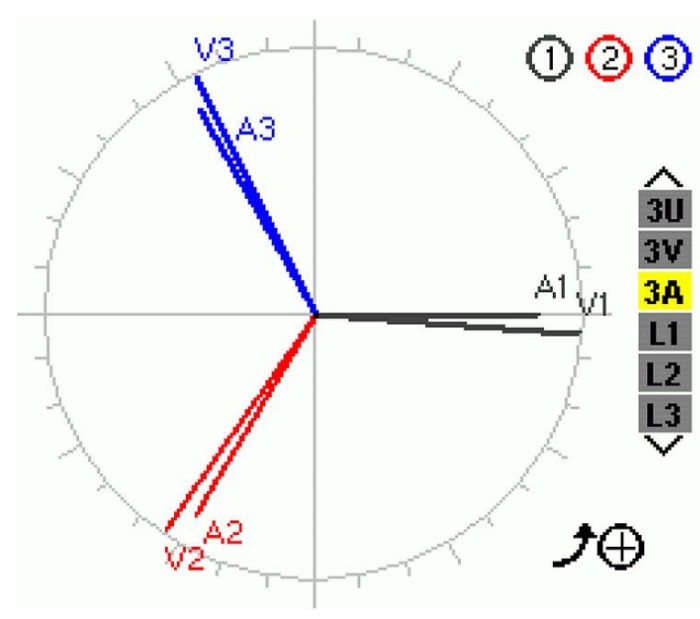

Fig. 10. Fresnel diagram of the voltages and currents in $37^{\text {th }} \mathrm{s}$

\section{Possible improvement}

The excitation current of the synchronous condenser (synchronous condenser) is not controlled here and probably not even stabilized. It would certainly be possible to control the excitation current of the synchronous condenser so that the values of the reactive consumption of the rolling mill were as small as possible. Working range of the compensating possibility of the synchronous condenser is $6.5 \mathrm{Mvar}$ of the reactive consumption. In the above-mentioned longer part of the cycle, 2 Mvar of capacity consumption are missing, so the required reactive consumption of the compensator would not exceed 3 Mvar, which is only about half of the achievable value of its possible reactive consumption. In the shorter part of the cycle, when the rolling mill is overcompensated, it would be possible to eliminate this unnecessary overcompensation by reducing the reactive consumption of the synchronous condenser $Q_{4}$ by about 0.7 Mvar. This is less than the minimum measured value of the reactive consumption of the synchronous condenser $Q_{4}$.

\section{Conclusion}

It is possible to conclude that the available control range of the synchronous condenser during the monitored operation of the rolling mill could be used to put down the unfavourable reactive consumption of the rolling mill. With a different profile of the final rolled product, the individual consumption values may probably be quite different. Therefore, it would be necessary to verify whether the findings on the possibility of suppressing unfavourable consumption are always valid by long-term monitoring of the total consumption of the rolling mill.

In the next step, it would be necessary to verify the possibility of setting the required value of the excitation current online. Then it would be possible to design, implement and tune a suitable stable controller.

\section{Acknowledgment}

This work was supported by the Project SP2021/84 of the Student Grant System, VŠB - Technical University of Ostrava.

\section{References}

[1] Ispat Guru, https"//www.ispatguru.com/rolling-mill-andits-technological-equipments/. Last accessed 16 Juny 2020.

[2] V. Chura, Elektrotechnika pro horní a hutní inženýry, SNTL Praha 1972, DT 621.3.669.

[3] V. Kůs, Vliv polovodičových měničů na napájecí soustavu, BEN - Technická literatura, Praha 2002, ISBN80-7300-062-8.

[4] Z. Hradílek, Elektroenergetika průmyslových a distribučních zařízení, VŠB-TU Ostrava, 2008, ISBN 978 80-7225-291-6.

[5] L. Cigánek and M. Bauer, Elektrické stroje a př́istroje, SNTL Praha 1955, DT 621.313+621.314.2+621.316.5.

[6] C.A 8335 Qualistar+, CHAUVIN ARNOUX User's manual, 2011. 